\begin{tabular}{l} 
REsumo \\
Esta pesquisa envolve a análise \\
das práticas de ensino com uma \\
dupla referência: à didática e \\
à Psicanálise. O conceito de \\
"relação com a prova” (rapport \\
à l'épreuve) permite explicar o \\
significado atribuido por uma \\
professora especializada à sua \\
experiência com um grupo do \\
Instituto Terapêutico, Educa- \\
cional e Pedagógico (ITEP) na \\
França. Aplicação didática, \\
sujeito suposto saber, impossível \\
de suportar são as três dimensões \\
que estruturam a relação com a \\
prova nesse espaço-tempo com \\
os alunos, cujo maior desafio \\
é a transmissão do saber. O \\
estudo de caso mostra como, de \\
uma forma sempre singular, um \\
sujeito confronta o seu desejo \\
de transmissão com a prática \\
de ensino. \\
Descritores: práticas de ensi- \\
no; ensino especializado; relação \\
com a prova; didática clinica; \\
estudo de caso. \\
\hline
\end{tabular}

\section{ENSINAR EM ESTABELECIMENTO ESPECIALIZADO: RELAÇÃO COM A PROVA̧ E POSIÇÃO SUBJETIVA DO PROFESSOR}

$\mathbb{C}_{\text {sta pesquisa }}{ }^{1}$ faz parte dos trabalhos realizados no campo das Ciências da Educação e trata da análise das práticas dos professores sob a ótica da Psicanálise. Nossa proposta inaugura o uso de analisadores da didática clínica para o estudo das práticas de professores especializados.

O Instituto Terapêutico, Educacional e Pedagógico (ITEP) constitui um contexto particular para o exercício da profissão docente, uma vez que ele atende crianças e adolescentes portadores de deficiências psíquicas, cuja expressão, sobretudo a intensidade de problemas comportamentais, perturba seriamente o acesso à aprendizagem. 
A contingência inerente a qualquer situação didática adquire aqui uma ressonância particular e suscita o nosso questionamento. Como ensinar quando os alunos apresentam esses obstáculos em sua relação com o saber e a aprendizagem?

Nós nos apoiamos no estudo de caso de uma professora para entender como, de uma maneira sempre singular, um sujeito confronta seu desejo de transmissão com a prova do ensino.

\section{Visão teórica}

Nosso estudo inscreve-se no âmbito de pesquisas que recorrem à Psicanálise para pensar as questões relacionadas à educação, ao ensino ou à aprendizagem. Ele se situa, mais precisamente, dentro da perspectiva desenvolvida pela Equipe de Pesquisa em Didática Clínica (EDIC), cujos trabalhos estudam as práticas de ensino e a percepção da subjetividade dos professores no sistema didático (Terrisse e Carnus, 2009). Assim, nossas referências são tanto didáticas quanto clínicas, pois elas sustentam uma abordagem psicanalítica das questões didáticas de ensino; trata-se de compreender o processo pelo qual um professor transmite (ou não) os conhecimentos que ele deseja que os seus alunos aprendam, considerando a dupla determinação da circunstância didática, produzida por "restrições externas", relacionadas ao sistema didático (Amade-Escot e Marsenach, 1995), e por "restrições internas", próprias de um professor em particular (Beillerot, Blanchard-Laville \& Mosconi, 1996). Essa dupla determinação, inscrita no cerne das práticas dos professores, nos motiva a adotar como referência os conceitos do campo da Psicanálise; estes podem, de fato, nos oferecer uma pista para examinar a complexidade do ato de ensinar, algo que a didática, com seus instrumentos próprios, não nos permite explicar.

É nessa perspectiva que Terrisse (1994), na sequência dos trabalhos de Brousseau (1990), propõe uma reescrita do triângulo didático, incluindo a parte da impossibilidade de transmissão total.

A prova, que substitui o saber no esquema revisado, acentua a dimensão das restrições internas e a atenção focada na posição subjetiva do professor. O saber, agora situado no encontro dos três polos (professor - aluno - prova), é visto como "não totalmente transmissível", incluindo uma parte irredutível de desconhecimento. A contingência ligada à situação didática é revelada nessa concepção, 
saber

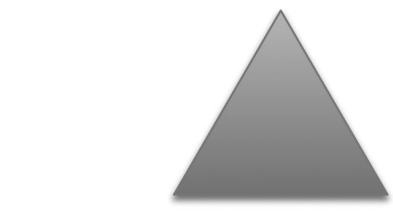

professor

0 triângulo didático prova

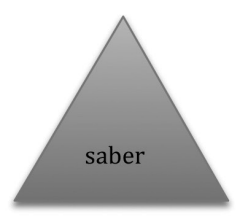

professor

aluno

0 triângulo didático revisado

(Terrisse, 1994) o que nos parece abrir espaço ao estudo das relações entre o desejo de transmissão do professor, a missão que lhe é conferida pela instituição escolar e o confronto de ambos na prova real de uma classe. Essa concepção também oferece perspectivas para estudar as modalidades de constituição do desejo de aprender das crianças e adolescentes, o qual é confrontado com visíveis obstáculos na realidade da classe. Nossa pesquisa situa-se, precisamente, no primeiro desses eixos.

A relação com a prova (rapport à l'épreuve) (Jourdan e Brossais, 2011) se apresenta como um conceito heurístico para estudar a complexidade do ato de ensinar, das escolhas que o professor tem que fazer e dos espaços de criatividade que se abrem a ele. Esse conceito permite apreender o significado que os professores atribuem ao que eles vivem em classe, nesse espaço-tempo de interações com os alunos cujo retorno é a transmissão do saber. "Conversão didática", "sujeito suposto saber" e "impossível de su- portar" aparecem como as dimensões estruturantes da relação com a prova nos testemunhos dos professores estagiários.

$\mathrm{Na}$ didática clínica da Educação Física e Esportiva (EFE), Buznic-Bourgeacq, Terrisse e Margnes (2010) propõem o termo "conversão didática" para explicar a transformação do conteúdo da experiência em conteúdo de ensino. Os elementos do saber construídos pelo professor em sua experiência pessoal organizam o conteúdo das suas práticas efetivas de ensino. Assim, o professor transmite não apenas os saberes, mas também algo de sua própria relação com esse tipo de saber.

Nossa hipótese, na prova de ensino, é que o professor é colocado na posição do sujeito suposto saber (Lacan, 1966). Existe, portanto, toda a dificuldade de uma "posição de professor [que] é chegar a exercer uma lei, a da transmissão dos saberes, sem, contudo, encarnar ele mesmo o saber" (Delanoé e Labridy, 1983, p. 33). Na situação de ensino, o profes- 
sor ocupa a função de alguém a quem é suposto que detenha e transmita o conhecimento. Trata-se, não apenas do conhecimento disciplinar, mas também do conhecimento sobre o que é um aluno e sobre o que um aluno deve saber. Assim, a maneira como o professor ocupa esse papel de sujeito suposto saber vai estruturar, sem que ele saiba, sua relação com a prova.

Em seu trabalho, o professor é confrontado a um impossível de dizer, de fazer, de transmitir (Freud, 1925/1973). O impossivel de suportar (Lacan, 1977) traduz, para nós, o impedimento que o sujeito professor pode encontrar para manter o equilíbrio que lhe permite preservar o seu lugar de professor. O impossivel de suportar pode se manifestar na ação do professor. No entanto, o mais comum é que ele apareça na demonstração de emoções (medo, tédio, pena, raiva, violência, vergonha, prazer, exaltação) que demonstrem, também, a confrontação do professor com o impossível.

Neste estudo, interessamo-nos pela relação com a prova de uma professora especializada que trabalha em uma unidade de ensino no ITEP, instituição situada na França e dedicada a atender "crianças, adolescentes ou jovens adultos com dificuldades psicológicas, cuja expressão, sobretudo a intensidade de problemas comportamentais, perturba seriamente a socialização e o acesso à aprendizagem" (Decreto no 2005-11, 6 de janeiro de 2005).

Apesar de ser cada vez mais recorrente crianças e adolescentes com deficiência frequentarem escolas e colégios, conforme defende a política de inclusão escolar na França, muitos continuam realizando parte ou mesmo a totalidade de sua educação nas unidades de ensino desses estabelecimentos. A tríplice missão das unidades do ITEP requer uma equipe multidisciplinar composta por profissionais da saúde, da área social e da educação. Nesses estabelecimentos, o professor fica face a face com crianças e adolescentes cujo equilíbrio psíquico é afetado pelas exigências inerentes à situação de aprendizagem; as limitações psíquicas representam obstáculos reais para o acesso ao saber e para a relação com o outro. Esse empecilho para aprender é, frequentemente, associado a uma grande agitação ou a uma extrema passividade.

Com essa proposta, desejamos observar a pertinência dos nossos analisadores em um contexto diferente daquele em que eles foram criados e atualizados: a área da adaptação escolar e da escolarização de alunos com deficiência.

Como os professores que trabalham no ITEP são levados a se submeter a essa prova? Como esses professores se esforçam para transmitir os conteúdos do saber escolar a alunos que se recusam ou se opõe a aprender? Como os sujeitos professores se ajustam a essa impossibilidade de transmissão aqui expressa?

Nossa postura clínica de pesquisadores em Ciências da Educação é apoiada pela referência à prática 
psicanalítica, na qual o analista se deixa ensinar pelo analisante. De forma análoga, queremos nos deixar ensinar pelo que dizem os professores cujas práticas profissionais nós buscamos explicar.

Nós nos interessamos, particularmente, em observar e compreender as invenções próprias de cada professor na prova de ensino, ou seja, o desenvol, vimento do saber-fazer na situação (savoir-y-faire).

\section{Metodologia}

Nossa equipe de pesquisa trabalha por meio de entrevistas e observações filmadas das práticas de classe, respeitando três fases cronológicas: uma entrevista antes da sessão, uma observação da prática de classe e uma entrevista pós-sessão. Neste artigo, apresentamos a análise de uma entrevista antes da sessão, a primeira fase da metodologia da didática clínica (Carnus e Terrisse, 2013).

O roteiro da entrevista semiestruturada, desenvolvido coletivamente, visa coletar, no momento do encontro pesquisador-professor, a fala de um sujeito sobre sua maneira particular de passar pela prova.

Nossa metodologia de análise permite contemplar a dimensão da opacidade da linguagem, que não é reduzida aos significantes. Muitos estudos em Ciências Humanas e Sociais consideram a linguagem transparente, ou seja, como sendo um mero veículo ou suporte de informações. Nossa referência à Psicanálise, todavia, nos leva a pensar o sujeito como representado na linguagem, sendo que a sua enunciação é a marca dessa representação na linguagem.

A nossa análise é, portanto, baseada em:

- indícios significativos em relação às nossas três áreas temáticas;

- indícios detectáveis com as ferramentas dos estudos linguísticos (modalizadores, repetição, recorrência, campo lexical, conotação/denotação, pronomes pessoais, figuras retóricas);

- indícios característicos da enunciação do sujeito segundo a Psicanálise (lapsos, "brancos", hesitações, associações).

\section{O estudo de caso}

Nesta seção, apresentamos a análise da relação com a prova da Natacha. Trechos significativos da posição subjetiva dessa professora são apresentados para construir o caso e são organizados, principalmente, a partir de três analisadores: 
conversão didática, sujeito suposto saber, impossível de suportar. As citações retratam as tensões da professora confrontada com a prova real da classe e também revelam o saber-fazer na situação implementada por ela.

Professora de escola há 15 anos, Natacha lecionou, inicialmente, em uma escola primária, onde trabalhou durante dois anos, até que, sem ter solicitado, foi nomeada para trabalhar em uma instituição especializada. Depois de dois anos na instituição, ela voltou para "uma escola regular no subúrbio": "eu não gostei nadinha e o olhar dos professores sobre as crianças e o olhar dos parentes sobre os professores ...". Ela voltou então "muito rapidamente para o especializado": "Então, até o olhar sobre as famílias e sobre as crianças é muito mais benevolente que no setor regular, pelo menos em comparação com as experiências que eu pude ter no setor regular". Há 10 anos, ela ensina no mesmo ITEP: "a deficiência... en sabia que ia me envolver um dia e... distúrbios do comportamento, isso me agradou e eu preferi ficar aqui'. Há três anos, ela obteve o CAPA-SH (certificado de aptidão profissional para as ajudas especializadas, os ensinos adaptados e a escolarização de alunos portadores de deficiência), depois de um ano de formação em alternância. Natacha associa essa escolha de orientação da sua vida profissional com a sua própria história: "eu tenho um pai educador e mergulhei nesse meio bem pequena e pra mim cuidar dos outros e daqueles que estão em dificuldade é algo natural'.

\section{Ler os clássicos/escrever histórias - conversão didática}

As experiências pessoais de Natacha como aluna organizam suas práticas profissionais. "A literatura eu adoro isso": o gosto de Natacha pela literatura a leva a fazer escolhas de obras literárias que ela qualifica como "literatura de verdade" e "bistórias de verdade". Romeu e Julieta, de Shakespeare, e Os Três Mosqueteiros, de Alexandre Dumas, são as peças de teatro que ela escolhe para trabalhar, classificando-as de "bistórias fortes", suscetíveis de tocar os seus alunos: "isso mexe com eles". Ela contrasta essa literatura, fruto "da cultura e do patrimônio", com os romances juvenis, "francamente vazios no nivel do estilo, no nivel do conteúdo, no nivel da história".

Ela faz referência ao seu passado como aluna para promover a leitura dos clássicos: "eu acho que os clássicos devem ser lidos". Ela se

564 Estilos clin., São Paulo, v. 18, n. 3, set./dez. 2013, 559-573. 
define como uma "aluna comum" que "viu apenas o lado forçado" das leituras. Ela explica referindo-se à sua "falta de maturidade". Mas ela "lamenta não ter sido mais séria no colégio" e ter "apenas lido por cima vários livros". Ficando "muito no escolar", ela "nunca se deixou levar pela produção da escrita": "eu poderia ter curtido muito bancar a escritora, eu não ousei".

Natacha vive como professora aquilo que ela não pôde viver como aluna: "agora posso me soltar... devanear realmente, escrever histórias". Ela menciona a criação artística, plástica e literária: "aconteceu-me de faz̧er produções de artes plásticas com as crianças e em seguida recuperar as producões e inventar uma bistória, algo que eu me permito agora como professora, mas que eu não me permitia como aluna". O uso do pronome reflexivo "me" associado a "com as crianças" produziu um efeito ambíguo: quem criou? Seus alunos? Ela mesma? Ambos? Portanto, fazer parte de um espaço de criação com seus alunos constitui um dos saber-fazer na situação de Natacha.

\section{O professor e o saber: "emana do lógico"2 - o sujeito suposto saber}

Para Natacha, ser aquela que transmite os saberes está ligado a "ter uma certa autoridade" sobre os alunos. Sua "reputação de professo$r a$ " na escola é construída com o tempo: "com os pequenos é preciso que eles estejam lá há dois ou três anos para me reconbecer, saber quem eu sou". Essa imagem de autoridade anda junto com a imagem que os alunos criam sobre o nível de dificuldade dos conteúdos: "essa é a imagem que algumas crianças criam, na minha classe é muito difícil". Quando Natacha declara "para me reconhecer, saber quem eu soü", nós nos perguntamos se essa identificação vale mesmo para os seus alunos ou, na verdade, apenas para si mesma.

Natacha, em sua posição de sujeito suposto saber, expressa uma preocupação diante da obrigação de ter que ensinar uma disciplina que lhe escapa: "eu perdi tanto, e o inglês eu sempre tive uma apreensão". Natacha almeja recuperar essa perda relacionada ao saber: "eu tenho muita coisa a retomar".

Diante dos saberes com os quais ela "se sente menos confortável", Natacha não é a única pessoa suposta saber. Ela pode compartib lhar esse lugar com uma colega: "ela fez uma formação em Ciências 
e muitas vezes quando as crianças fazem perguntas eu me volto para a minha colega". Ela atribui à sua colega esse papel de sujeito suposto saber por causa de sua formação em Ciências, a qual lhe fornece uma autoridade no campo. A própria presença do outro que sabe dá segurança a Natacha, e lhe permite superar o obstáculo que é para ela ensinar Ciências: "eu chego a entender como contornar o negócio".

Para ela, o professor não é o único a deter o saber e a transmiti-lo: "eu faço parte dos professores que pensam que têm o conbecimento inato e que são eles que devem transmitir o saber". Os educadores também podem fazer os alunos progredirem: "eu tenho um aluno que fez enormes progressos em leitura, eu sei muito bem que não é comigo que ele os fer". Natacha repete enfaticamente: "eu sei muito bem que não é o pouco tempo que ele passa comigo"; "eu estou convencida de que se ele melhorou tão rapidamente foi com 0 trabalho que ele fez com os educadores". O êxito com uma criança não pode ser atribuído unicamente a si mesma: "você poderia pensar que foi você que teve êxito com o garoto". O trabalho de equipe desperta a humildade: " $n a ̃ o$ sou só eu que serve para alguma coisa”. Mas essa situação afeta Natacha: "às vezes isso incomoda um pouco, mas bem (risos)".

Natacha se posiciona, entretanto, claramente como uma professora: " $a$ gente tem um saber-fazer e um método e a gente nem se dá conta e tem coisas que são óbvias para nós e emana do lógico". Esse lapso, uma contração de "emana do ser" e "é lógico", ocorre no momento em que Natacha se esforça para explicar o papel dos professores em relação aos outros profissionais da instituição. Ela distingue, aqui, explicitamente, os professores, cujo saber e método são sabidos, dos educadores, que são "um pouco imóveis", tendo à sua disposição apenas "truques" ou "um pouco de técnica" para lhes ajudar. Para Natacha, mesmo que os educadores possam fazer as crianças progredirem, é o professor que, sozinho, detém e transmite o saber. Natacha acredita que seria "constrangedor" se outro profissional "se achasse responsável pela missão de ensinar e tentasse fazer as coisas no nosso lugar". No entanto, ela dá valor ao que é feito por uma educadora: "en o coloquei (o trabalho de conjugacão) na pasta de atividades", mas lhe atribuí um lugar secundário: "eu não coloquei com as atividades que fazemos em classe, mas eu coloquei no final da pasta".

Perante os alunos que questionam o conhecimento que ela transmite, Natacha se afirma como aquela que detém o saber incontestavelmente: "sinto muito por insistir, mas o Japão fica mesmo na Ásia, eu acho que estou um pouco convencida".

Ao mesmo tempo, ela reconhece, diante dos seus alunos, não saber ou se confundir: "não é grave, hein, não é porque eu sou adulta e que eu son prof. que necessariamente eu sei tudo". Ela estima, inclusive, que reconhecer o seu não saber lhe garante, paradoxalmente, o respeito dos alunos: "eu acho que as crianças vão, de fato, lhe respeitar mais se você lhes mostrar que às vezes você não sabe, às vezes você se confunde". 
Natacha observa que o conhecimento pode ser um desafio psíquico para uma criança; é preciso cuidar da criança, potene cialmente presa em um conflito de lealdade entre dois "sujeitos suposto saber", o pai e o professor: "então en sei que às vezes tem o discurso dos pais que está por trás e que não se deve colocar, não se deve colocar o garoto entre os dois". É preciso cuidar da criança para que sua relação com o saber a conduza "realmente a contestar tudo": "eu sei dentro de mim que existe a patologia então não posso ser muito seca na minha maneira de responder".

Esse reconhecimento do saber, como desafio mental para a criança, não impede Natacha de ser afetada pela postura de um aluno que afirma saber tudo e, portanto, desafia o conhecimento que ela despende: "é a sua patologia, é um garoto que não tem confiança nele, que na verdade se coloca como alguém que sabe tudo ... é desagradável".

Natacha dá consistência ao conhecimento trazido pelos alunos e, assim, os valoriza como sujeitos que podem, também, saber: "as crianças, quando efetivamente têm razão, apreciam quando no dia seguinte você diz a elas: bem eu verifiquei, você tinha razão, isso existe, isso se escreve assim".

\section{Esquecimento, repetição e renúncias - o impossivel de suportar}

Em resposta à pergunta "o que significa ser professor no ITEP?”, Natacha apresenta uma resposta surpreendente: “é esquecer que você é professor". Esse paradoxo destaca, para ela, o abandono daquilo que forma sua identidade profissional, e dos saberes e do saber-fazer que estão vinculados a ela. Esse abandono é confirmado pela necessidade que ela exprime de ter tido que "reaprender completamente sua profissão".

Para Natacha, ser professora é "gerir a classe" e transmitir os conteúdos dos saberes escolares: "é preciso ter a didática por trás de você". A relação pedagogia-didática se traduz para ela em uma imersão dentro da pedagogia: "eu estou muito na pedagogia", e uma renúncia à didática que Natacha expressa no registro da falta: "isso começa a me fazer falta".

Natacha evoca, em um tom de obrigação, a repetição dos atos profissionais que ela vive: "você está sempre se adaptando", "você 
é obrigado a repetire repetire repetir", "você é obrigado a repetir'.

Ela menciona uma circunstância específica da instituição: "nunca são os mesmos (alunos) ao mesmo tempo", "finalmente as crianças nunca estão todas lá ao mesmo tempo". Essas restrições externas, próprias da instituição, lhe bloqueiam: "é um quebra-cabeça ... isso freia demais o trabalho".

Natacha expressa uma renúncia, instalada ao longo dos anos, do prazer que ela experimentava ao ensinar os seus alunos a cantar: "eu adoro cantar com meus alunos e desde que vim para o especializado não canto quase nunca". $\mathrm{Na}$ verdade, dois incidentes levaram-na a fazer essa escolha: "como estamos no ITEP, roubaram meu violão e depois estouraram as cordas do outro".

Apesar de trabalhar com alunos caracterizados por "dificuldades psicológicas cuja expressão são os distúrbios de comportamento", Natacha revela apenas nesse momento os episódios violentos que ela enfrenta em sua prática diária. Segundo ela, o que mais lhe afeta é a recusa dos alunos em trabalhar, quando manifestada pela inércia: "o que é duro é quando eles estão apáticos e sem vontade".

Natacha almeja que os alunos se tornem sujeitos capazes de pensar e de desenvolver suas opiniões, e que sua criatividade seja despertada; porém, por causa das características dos alunos, as coisas acabam não acontecendo como ela gostaria: " a literatura, eu adoro isso; alguns anos isso funciona ... eu tenho um monte de meninas que são muito passivas e que 
têm muita dificuldade em dar suas opiniões, empartir no seu imaginário etc., e a literatura com elas é uma luta". Observamos no corpus um acúmulo de expressões que manifestam as renúncias ao seu desejo de transmissão do conteúdo escolar: "eu verdadeiramente revi a literatura todinha", "eu não fiz nadinha do que eu tinha previsto no segundo periodo", "eu tenho muita dificuldade para iniciar em literatura", "en revisei tudinho do que en tinha previsto", "certos momentos você diæ: a gente não está avançando, não está avançando rápido".

No final da entrevista, o acúmulo de restrições externas, associado ao impedimento do seu desejo de transmitir o conteúdo, leva Natacha a perceber o peso que isso representa para ela: "são todas as disfunções da estrutura, todas as programacões que não são postas em prática no início do ano; eu disse: eu tenho muitas crianças na minha classe, ao mesmo tempo eu disse, en gritei mas nada foi feito, enfim tudo isso é superpesado".

Essa carga, sustentável até agora, marcada pelos termos "superpesado" e "pesar", tornou-se uma sobrecarga: "confesso que até hoje o fato de não avançar rápido com as crianças eu vivia até que bem, mas agora, desde um ou dois anos, isso começa a me pesar'.

Sua insistência em falar sobre as disfunções institucionais, marcada pela gradação "eu disse ... eu disse, eu gritei”, permanece sem efeito.

O impossível de suportar para Natacha é caracterizado pelo transbordamento, causando um ponto de inflexão que a leva a decidir deixar a educação especializada: "eu tenho vontade de voltar ao regular". A classe "regular" representa um possível renascimento de sua atividade profissional: "en saturei um pouco do especializado, por isso en preciso recarregar minhas baterias ... isso não quer dizer que é definitivo e que en não retornarei mas é sim neste instante...".

O ensino regular parece ser uma normalidade ideal, em que ela poderá encontrar "crianças que pegam o caderno quando você fala para pegar o caderno são coisas bem simples, mas as crianças não vão balançar suas cadeiras porque você disse não a elas". Voltar para a escola regular coincide, para Natacha, com a ideia de reencontrar o seu desejo de transmitir o conteúdo dos saberes escolares e de retomar a didática: "é mais puxado sabe... os conhecimentos em que você chega... a música, a literatura eu curto mais com o ensino fundamental II do que com o ensino fundamental I com relação aos conteúdos".

\section{Discussão - Ensinar no ITEP: instruir ou cuidar?}

A análise do relatório com a prova de Natacha nos permite abordar a complexidade do ato de ensinar para uma professora do ITEP.

Ensinar no ITEP deve atender a duas necessidades: transmitir o conteúdo dos saberes escolares aos alunos e cuidar das crianças e dos adolescentes da classe. A tensão criada por esses dois movimentos é característica do relatório com a prova da Natacha, e determina a alternância de sua traje- 
tória profissional entre o ensino regular e o ensino especializado.

Natacha associa à sua própria história sua escolha de se engajar no ensino de crianças e adolescentes portadores de dificuldades psíquicas. A referência ao seu pai e à sua profissão de educador desempenhou, nesse ponto de vista, um papel decisivo. Nas suas primeiras experiências em uma escola "regular", Natacha observa a ausência de "benevolência" no olhar sobre as crianças e sobre os pais, bem como sobre os próprios professores. Essa benevolência que ela encontrou na instituição especializada atende à necessidade, "natural" para ela, de cuidar "daqueles que estão em dificuldade".

Esse movimento, que motiva o seu engajamento no especializado, é confrontado com a restrição de ter que, por ser professora, transmitir conteúdos do saber escolar para alunos com graves dificuldades para aprender.

Analisado sob a ótica da conversão didática, seu desejo de transmissão da literatura parece enraizado no seu gosto pela leitura e pela cultura literária, e a leva a escolher obras "de verdade", capazes de "tocar" os seus alunos.

Essa escolha, no entanto, é dificultada pela passividade dos adolescentes da classe, os quais se opõem a investir o seu esforço nesses objetos escolares. Assim, o impedimento da transmissão expressado por Natacha, em termos de renúncias repetidas, ecoa o impedimento de aprender demonstrado pela passividade dos seus alunos.

Saber transmitir é para Natacha o fundamento de sua profissão e forma sua identidade profissional. Esse saber, que "emana da lógica" para o professor, exige um certo domínio dos conteúdos a serem ensinados, um método e alguns saber-fazer. Ocupar uma posição de sujeito suposto saber não reflete, para Natacha, uma necessidade de incorporar, ela mesma, o saber: outros podem saber (educador, pai, psicólogo, criança) e ela mesma pode não saber.

O esquecimento do que forma sua identidade profissional é, porém, apresentado por Natacha como a única solução para poder enfrentar a prova da classe e do encontro com os alunos. O equilíbrio entre didática e pedagogia é instável, e a dimensão pedagógica "gerir" muitas vezes prevalece sobre a transmissão de conteúdos do saber escolar. Associado às fortes restrições externas, esse equilíbrio parece, agora, insustentável para Natacha, constituindo um impossível de suportar que motiva a sua escolha de deixar a instituição. Voltar para uma escola "regular" parece uma ação que lhe permitirá "recarregar as baterias", ainda que ela pretenda voltar um dia para o ensino especializado. 
Desse modo, partir e depois retornar do ensino regular ao ensino especializado traduz, para Natacha, uma tensão entre dois movimentos que caracterizam sua relação subjetiva com a prova da classe e da sua profissão de professora. As idas e vindas de uma instituição à outra acompanham, para ela, esse duplo movimento: instruir seus alunos transmitindo conteúdos do saber escolar e levar em conta a relação com o saber e a aprendizagem das crianças e dos adolescentes que lhes são confiados.

Ao fazer isso, ela coloca em prática sua maneira singular de enfrentar a contingência inerente a qualquer situação didática.

\section{Conclusão}

A análise dessa primeira entrevista nos permitiu obter elementos de respostas para as perguntas que nos fizemos. Responsável por ensinar crianças e adolescentes que se opõem à escolarização regular, Natacha oscila entre cuidar dos seus alunos e transmitir os conteúdos do saber escolar a eles. A manutenção desse equilíbrio exige, de Natacha, idas e vindas entre o ensino regular e o ensino especializado.

A partir deste estudo, já podemos concluir que o conceito de relação com a prova, através das três dimensões, faz a função de analisador teórico da subjetividade do professor e do significado que ele dá à prova real de uma classe. Fazer parte de um espaço de criação com seus alunos, baseando-se nos clássicos da literatura, reflete a conversão didática de Natacha. Compartilhar o lugar daquele que sabe com seus colegas, os pais e os próprios alunos, enquanto mantém a posição de autoridade do professor, na sua função de transmissor dos saberes, caracteriza a dimensão sujeito suposto saber. O esquecimento de sua própria identidade de professora, associado ao acúmulo de restrições institucionais, constitui um impossivel de suportar para Natacha.

A observação das sessões de classe filmadas pela professora, seguida de uma entrevista après-coup, nos permitirá maior concentração nos "saber fazer na situação" colocados em prática na situação didática.

Pertinente para estudar o que os professores iniciantes vivem em classe, o conceito de relação com a prova também permite explicar a complexidade do ato de ensinar crianças e adolescentes confrontados 
com sérios obstáculos no acesso ao conhecimento. Assim, a análise das entrevistas conduzidas com outros três professores de uma instituição especializada nos dará a oportunidade de desenvolver e aprofundar o estudo das práticas de professores especializados; no nosso ponto de vista, esse estudo pode trazer uma elucidação heurística e praxiológica para a formação de professores de escolas e colégios, os quais são, atualmente, em muitos países, compelidos a receber alunos com necessidades educacionais especiais em suas classes. De fato, a atualidade da inclusão escolar, particularmente no Brasil e na França, revela os obstáculos enfrentados pelos professores envolvidos na educação de crianças e adolescentes portadores de dificuldades psíquicas (Pechberty, Kupfer, \& Jonquière, 2010).

A referência à Psicanálise nos leva a considerar que o mais singular em uma experiência pessoal pode confirmar a universalidade de toda condição humana (Terrisse, 2000). A sua elucidação, na perspectiva da didática clínica, mostra aqui a sua fecundidade para abordar a complexidade das práticas do professor.

TEACHING IN SPECIALIZED ESTABLISHMENT: RELATIONSHIP IN THE EVENT AND THE SUBJECTIVE POSITION OF THE TEACHER

\section{Abstract}

This research concerns the analysis of the teaching practices, with the double didactic reference and the psychoanalysis. The concept of relationship in the event allows to report the sense which awards a teacher specialized in what she lives in a class in Therapeutic, Educational And Educational Institute (ITEP) in France. Didactic conversion, supposed subject to know, impossible to support are three dimensions which structure the relationship in the event, in this spacetime with the pupils the major stake in which is the transmission of the knowledge. The case study shows bow, in a always singular way, a subject confronts its desire of transmission with the event of the teaching.

Index terms: teaching practices; special education; relationship in the event; clinical didactic; case study.

ENSEÑAR EN ESTABLECIMIENTO ESPECLALIZADO: RELACIÓN A PRUEBA Y LA POSICIÓN SUBJETIVA DEL PROFESSOR

\section{REsúmen}

Esta investigación radica en el análisis de las prácticas de enseñanza, con la doble referencia: en didáctica y en psicanálisis. El concepto de «relación a prueba» permite dar cuenta del significado que atribuye una profesora especializada en cuanto a su experiencia con un grupo de Instituto Terapentico, Educativo y Pedagogico (ITEP) en Francia. Aplicación didáctica, sujeto con supuestos conocimientos, imposible de soportar son las tres dimensiones que estructuran la relación a prueba, en este espacio-tiempo con los alumnos cuyo desafio mayor es la transmisión del saber. El estudio de caso revela cómo, de manera siempre singular, un sujeto confronta su deseo de transmisión con la práctica en la enseñanza.

Palabras claves: practicas de enseñanza; enseñanza especializada; relación a prueba; didáctica clínica; estudio de caso.

\section{REFERÊNCIAS}

Amade-Escot, C. \& Marsenach, J. (1995).

Didactique de l'éducation physique et sportive: questions théoriques et méthodologiques. Grenoble: La Pensée Sauvage/INRP.

Beillerot, J., Blanchard-Laville, C. \& Mosconi, N. (Orgs.). (1996). Pour une clinique du rapport an savoir. Paris: L'Harmattan. 
Brousseau, G. (1990). Le contrat didactique et le concept de milieu: dévolution. Recherches en Didactique des Mathématiques, 9 (3), 309336. Grenoble: La Pensée Sauvage.

Buznic-Bourgeacq, P., Terrisse, A. \& Margnes, E. (2010). La transmission du savoir expérientiel en EPS: études de cas et analyses comparatives en didactique clinique. eJRIEPS, 20, 26-47.

Carnus, M.-F. \& Terrisse, A. (2013). Didactique clinique de l'EPS : le sujet enseignant en question. Paris: Edition EP\&S.

Delanoé, M.-H. \& Labridy, F. (1983). Formation des enseignants d'EPS et psychanalyse. Revue EPS, 184, 31-34. Paris: Ed. Revue EPS.

Freud, S. (1973). Préface. In A. Aichhorn, Jeunesse à l'abandon (pp.3-6). Toulouse: Privat. (Trabalho original publicado em 1925)

Jourdan, I. \& Brossais, E. (2011). Du rapport au savoir au rapport à l'épreuve: le point de vue de deux professeurs stagiaires à l'IUFM, Recherche \& formation, 66, 9-22.

Lacan, J. (1966). Écrits. Paris: Seuil.

Lacan, J. (1977). Ouverture de la section clinique, Ornicar?, 9, 7-14.

Decreto n. 2005-11. (2005, 6 de janeiro). Estabelecendo as condições técnicas de organização e funcionamento dos institutos terapêuticos, educacionais e pedagógicos, Ministère des solidarités, de la santé et de la famille. Recuperado de http://www. legifrance.gouv.fr/WAspad/UnTexteDeJorf?numjo $=$ SANA0424186D.

Pechberty, B., Kupfer, C. \& de La Jonquière, L. (2010). La scolarisation des enfants et des adolescents dits «en situation de handicap mental» au Brésil et en France: convergence des recherches cliniques, Cliopsy, 4, 7-20.

Terrisse, A. (1994). La question du savoir dans la didactique des APS: essai de formalisation. Note de synthèse pour l'Habilitation à Diriger des Recherches, Toulouse, France: Université Toulouse III.

Terrisse, A. (2000). Epistémologie de la rei cherche clinique en sport de combat. In A. Terrisse (Org.), Recherches en sports de combat et en arts martiaux (95-108). Paris: Editions Revue EPS.

Terisse, A. \& Carnus, M.-F. (2009). La didactique clinique de l'EPS: enjeux de savoirs. Bruxelles: De Boeck

\section{NOTAS}

1. Pesquisa realizada por F. Savournin, E. Brossais e I. Jourdan na Unidade Mista de Pesquisa "Ensino, formação, trabalho, conbecimentos" da Universidade de Toulouse II - Le Mirail.

2. No texto original, a professora entrevistada menciona a expressão "ça va de source", que seria uma contração de "ça coule de source" e "ça va de soi". florence.savournin@univ-tlse2.fr 127, chemin de Tucaut 31100 - Toulouse - França.

Recebido em agosto/ 2013. Aceito em outubro/ 2013. 